\title{
Content-organizing Metadiscourse in Malaysian Undergraduate Engineering Lectures: Towards Improvement of Lecture Delivery
}

\author{
Noor Mala Ibrahim* \& Ummul Khair Ahmad \\ Language Academy, Faculty of Social Sciences and Humanities, Universiti Teknologi Malaysia, 81310 UTM \\ Johor Bahru, Johor, Malaysia
}

Submitted: 03/11/2019. Revised edition: 26/11/2020. Accepted: 26/11/2020. Published online: 30/12/2020

\begin{abstract}
The continuing importance of the English language has resulted in a growing number of academic lectures being delivered in English. Academic lectures, which are commonly associated with information-loaded delivery by an authoritative figure trying to impart knowledge instrumental for some future undertakings of the audience i.e. students, continue to become a subject of interest due to their precariousness contributed by many different forces (e.g. subject matter, instructors, students, technology, etc.). With English as the medium of instruction, academic lectures provide many other aspects of interest to researchers and one of them concerns lecture comprehension problems faced by students. Students vary in their English language proficiency, but the demands expected of them to function in an academic lecture conducted in English are the same. This chapter reports on how Malaysian lecturers organize their academic lectures, by focusing on the discourse functions of managing topics and managing phoric using the linguistic framework of metadiscourse. Findings show that lecturers are sensitive to the needs of their students to follow the lectures and the demands of academic lectures. The pedagogical implications based on the findings are presented.
\end{abstract}

Keywords: Engineering lectures, discourse structuring devices, Malaysian classrooms, metadiscourse

\section{INTRODUCTION}

Research into academic discourse, particularly on academic lectures have continued to receive the attention of researchers perhaps due to the internationalization of higher education, the popularization of English as a medium of instruction in contexts of ESL and EFL and the drive to understand how lecture comprehension is achieved and consequently how students could be helped. In some contexts, spoken corpora like MICASE (Simpson and Swales, 2001), BASE (Nesi, 2012) and ELFA (Mauranen, Hynninen, \& Ranta, 2010) have become a major catalyst for various investigations into what actually happens in lecture halls. As the mentioned corpora have facilitated ample research into academic lectures in their contexts, in settings such as Malaysia, similar research is still lacking partly obvious because of the challenges associated with collection of data 
and thus the lack of available corpora for analysis. In fact, the task of getting approval to record lectures alone has contributed a major hurdle as most lecturers are reluctant to have their classes being recorded, particularly when the language used, i.e. English is to be scrutinized - as they perceived (Ibrahim, 2015). The continuous lack of evidence on how lecture-related activities are conducted therefore persists and consequently efforts to improve lectures, particularly on language use based on real occurrences may also be restricted.

One area that triggers the necessity to conduct academic lecture research is the need to assist students to comprehend lectures. It is evident that the main interest in academic lecture research conducted so far has always been on how to help students understand lecture contents, and in the non-native context the need is even more crucial since many students are challenged by their lacking in English. This paper aims to provide insight into how lecturers in Malaysian higher learning institutions use language to guide students in comprehending engineering lectures.

\section{LECTURES AND ENGLISH AS A MEDIUM OF INSTRUCTION}

While an academic lecture is generally seen as an information delivering session with the objective of imparting knowledge to a group of students using various methods, it is actually a complex genre precariously characterised by various important variables. There is a heavy amount of information that students have to process, while perhaps simultaneously taking down notes on what is relevant. In addition, the contents which most of the time derived from written texts (textbooks, journal for examples) are commonly accompanied by a variety of multimodal aids which add demand to students' processing load. Academic lecture is also rich with spoken features that students need to recognize like "irregular pausing, false starts, hesitations, stress and intonation patterns" (Flowerdew, 1994: 10).

With its high degree of variability (MacDonald, Badger \& White, 2000), a lecture definitely creates challenges for students, and when the medium of instruction is not their mother tongue, students are further constrained in their comprehension.

Many studies have focused on discourse structuring devices (Thompson, 2003; Adel, 2010; Deroey and Taverniers, 2011), suggesting the intense interest on finding out how actually language is employed as tools to assist students dealing with lectures. Yet, studies on discourse structuring devices involving the Malaysian context is still limited, even though English as a medium of instruction, especially in the higher education institutions, has been implemented in the country for more than a decade (see Mohamed, 2008). This paper aims to fill this gap offering insights into Malaysian lecture halls and classrooms on the discourse structuring devices that Malaysian lecturers employed by paying particular attention on the manner in which they manage topics and phoric using the linguistic framework of metadiscourse. 


\section{METADISCOURSE}

Metadiscourse, defined loosely as discourse about discourse (Vande Kopple, 1985), has received substantial attention as it has become an important focal point when interaction is scrutinized, particularly in written discourse (Hyland, 2017). Despite the heavy attention, metadiscourse carries no precise definition and since researchers are in consensus that it is context-sensitive (e.g. Aguilar, 2008) and fuzzy, metadiscourse may be understood differently (Aquilar, 2008; Hyland, 2017). Generally, metadiscourse is agreed as linguistic devices that speakers use to shape the discourse and express attitudes (Aguilar and Marcia, 2002), to organise, describe and comment on the unfolding discourse (Mauranen, 1993), and to comment on the communicative situation and their roles in the situation (Adel, 2010). It is the ways speakers interact with their audience through their use of the language. Studies on metadiscourse has mostly centered on written discourses, particularly academic texts, covering extensively on research articles (RAs) (Hu and Cao, 2015; Salas, 2015) and students' written work either at school (Kim, 2017) or at tertiary levels (Kawase, 2015; Ali, 2016), and with some emphasis on other texts such as textbooks (Ebrahimi, 2018), as well as in relation to other language skills such as reading and listening (Dorodkhan and Kiasi, 2016). Metadiscourse in nonacademic texts have also been examined as in work on newspaper (Ahmed and Masroor, 2018), online consumer reviews (Vasquez, 2015), political talks (Albalat-Mascarell and Carrio-Pastor, 2019) and digital news (Pastor, 2016).

Metadiscourse in academic lectures that focuses on discourse structuring and organizing has been labelled in different names such as macromarkers (Chaudron and Richards, 1986; CrawfordCamiciottoli, 2007), introductory chunks (Khuwaileh, 1999), discourse organizers (Biber and Barbieri, 2007) or text-structuring metadiscourse (Thompson, 2003). Deroey and Taverniers (2011) argue that when lecturers have signals for clear organization of their lectures, it implies that lecturers have somewhat planned the speech, suggesting their awareness of the students' needs to be guided through the lectures. Considerations for the students through the use of metadiscourse portrays the interactivity and engagement in lectures which could facilitate comprehension. Thus, awareness and knowledge on how to clearly employ metadiscourse in lectures may help lecturers to turn lectures which are commonly seen as dry talks into engaging speeches that could help effectively improve comprehension among students. Conversely, being able to equip students with the knowledge on metadiscourse that lecturers used while lecturing may be key to helping students understanding lectures better.

Two discourse functions of metadiscourse that are associated with discourse structuring and organizing i.e. managing topics and managing phoric are the main emphasis of this paper. The discourse function of managing topics shows how lecturers introduce (sub)topics to be presented, conclude the (sub)topics when the discussion ends, and in some instances, highlight to students (sub)topics that should be excluded. This discourse function is important in lectures because by knowing the way (sub)topics are organized, the (sub)topics that are included or left out and the starting and ending segments of a (sub)topic, students are able to focus on the flow of the lecture. In other words, with these discourse functions students are provided guidance to go through the information-loaded talk that they listen to. 
The discourse function of managing phoric allows the audience to be referred to other parts of the text for further information (Hyland, 2005) and for linkages to contents that are salient to the on-going discussion to achieve the desired interpretation and comprehension of the text. Two most frequently found phoric markers in the literature are the ones that Crismore and Farnsworth (1990) termed as preview and review. Previews have an announcing function that signals to the audience what is coming, while reviews remind the audience what the speaker has done/said earlier in the speech. Using the same terms, Mauranen (1993) defines preview as clauses which contains an explicit indicator that a later part of the text is being anticipated and review as clauses which contain an explicit indicator that an earlier part of the text is being referred to. In brief, preview refers to the discourse forward and review refers to the discourse backward

In lectures, there are also instances where a reference looks simultaneously in both directions i.e. forward and backward and/or looks at the content from a bigger-picture perspective for better comprehension. Bunton (1999) termed these as overviews and they are examined in this paper. Another discourse function of managing phoric that is crucial in lectures is reminder i.e. the act of referring backward that a lecturer employs to achieve his didactical objective when transmitting knowledge. While reminder fulfils almost a similar function as review i.e. to refer to earlier part of the discourse, some different features merit reminders to be grouped in a separate sub-category. Thus, in this paper, phoric markers that are examined fall into four categories, namely review, preview, overview and reminder.

\section{METHODOLOGY}

The data for this investigation is composed of five university lectures delivered by Malaysian lecturers and compiled in a university setting in Malaysia. The contributors of the lectures were all male lecturers and they are all non-native speakers who at least have more than five years of lecturing experience. These five lectures were part of a corpus of engineering lectures compiled for a joined project funded by the British Council under the Prime Minister Initiative-II Fund. All the five lectures were for the second year courses and all of them covered the fundamental subjects of the Civil Engineering field. The focus on one particular field would essentially minimise the potential effects of variability of discipline on the discourse structuring metadiscourse used.

All these lectures were recorded, transcribed using a transcribing software, Transana (developed by the University of Wisconsin-Madison and could be subscribed at http://www.transana.org). The transcription later went through rigorous checking by various members of the said project. Table 1 details the sub-corpus analysed for this paper with information on the topics covered, the number of words per lecture and the duration of the lectures. 
Table 1 Details on lectures analysed

\begin{tabular}{|l|l|l|l|l|}
\hline No & Lecture ID & Lecture Topic & Duration & Word Count \\
\hline 1 & Lecture_1 & Equilibrium of Particles & $00: 47: 08$ & 5,045 \\
\hline 2 & Lecture_2 & Design of Restrained Beam & $01: 16: 49$ & 11,537 \\
\hline 3 & Lecture_3 & Aggregate, Water and Admixture & $01: 26: 40$ & 10,913 \\
\hline 4 & Lecture_4 & Space Truss & $00: 47: 42$ & 8,094 \\
\hline 5 & Lecture_5 & Combined Loadings & $00: 52: 42$ & 5,627 \\
\hline Total & & $\mathbf{0 5 : 1 1 : 0 1}$ & $\mathbf{4 1 , 2 1 6}$ \\
\hline
\end{tabular}

From the table, the total word count for all five lectures is 41,216 words which give an average of 132 words uttered by the lecturer per minute. While this rate falls in the range for acceptable speech rate of a lecture (see Tauroza and Allison, 1990) and a rate that is ideal for note taking, (see Robinson, Sterling, Skinner \& Robinson, 1997), processing the lecture in L2 plus the technicality of engineering vocabulary used may pose great demands on students processing the lecture contents, thus affecting the quality of listening comprehension.

As metadiscourse is a fuzzy concept and highly context-dependent, qualitative and interpretive approach (see Hyland and Jiang, 2018) was applied, looking at each transcript manually in identifying the metadiscourse that fulfils the functions of managing topics and managing phorics. Other than functional, the metadiscourse to be chosen must be overtly marked and refer to the current text. The small size of the corpus has made it possible to manually analyse all manifestations of metadiscourse: close scrutiny of lexico-grammatical items that serve the said discourse functions was undertaken and metadiscourse signals which stretched out from one-word signals to a full sentence have been identified and tagged. The tagged metadiscourse units were then extracted using a concordance software Wordsmith Tools (Scott, 2008) for enhanced reliability.

\section{FINDINGS AND ANALYSIS}

Table 2 provides a summary of frequencies for each type of discourse sub-functions that correspondingly serve to manage topics and manage phorics and the ensuing sections provide details on findings and analysis of the two discourse functions. 
Table 2 Frequencies of Occurrences of Managing Topics and Managing Phorics

\begin{tabular}{|l|l|l|l|l|l|}
\hline Discourse Functions & \multicolumn{2}{|l|}{ Discourse sub-functions } & \multicolumn{2}{l|}{ Total } \\
\hline \multirow{2}{*}{ Managing Topics } & $\begin{array}{l}\text { Introducing } \\
\text { Topics }\end{array}$ & $\begin{array}{l}\text { Concluding } \\
\text { Topics }\end{array}$ & \multicolumn{2}{|l|}{ Limiting Topics } & 199 \\
\cline { 2 - 5 } & 134 & 56 & 9 & Overviewing & \multirow{2}{*}{94} \\
\hline \multirow{2}{*}{ Managing Phoric } & Reviewing & Reminding & Previewing & 5 & \\
\cline { 2 - 5 } & 11 & 67 & 11 & & \\
\hline
\end{tabular}

Overall, there are about 199 instances of metadiscourse that functions as managing topic, normalized to 48.3 occurrences per 10,000 words. Introducing topics (134 instances or 32.5 occurrences per 10,000 words) dominates, followed by concluding topics (56 or 13.6) and limiting topics (9 or 2.2). For managing phoric, there are 94 instances (normalized to 22.8 occurrences per 10,000 words) across all five lectures, with reminders dominates (67 instances or 16.3 occurrences per 10,000 words), followed by reviewing and previewing (1leach or 2.7 occurrences each) and overviewing (5 or 1.2). From the figures of each discourse function, it is obvious that in structuring and organizing the lecture discourse, Malaysian lecturers much more frequently opted for discourse function of managing topics than for managing phoric, thus highlighting the more important function of the two in the Malaysian academic lectures.

\section{MANAGING TOPICS}

Being aware of what has happened and what will (not) happen during a lecture, students would be better prepared to process, and subsequently comprehend the information presented to them. The following presents the details of samples extracts in relation to management of (sub) topics taken from the five lectures.

\section{a. Introducing Topics}

Introducing the upcoming topic in lecture acts to explicitly announce to students contents that would be presented. Investigations on introduction of topics have been a common theme in studies examining lectures (e.g.: Chaudron and Richards, 1986; Crawford-Camiciottoli, 2007; Khuwaileh, 1999; Thompson, 2003; Molino, 2018; Liu and Chen, 2020). In these studies, topic introduction has either been treated as one single category or a multilayer category. While deciding introduction of topics as one single category offers a practical analysis procedure, unfortunately, the approach neglects the fact that lectures present a hierarchy of information on a particular topic. Consequently, 
by putting all introductions of topics into one category, linguistic behaviours of topic introductions occurring at various levels of the information delivery are ignored.

Thompson (2003) in her investigation of lecture introductions had three layers of topic introduction which she labeled as "global, and topical and sub-topical levels" (p.10). In the current investigation, it is also apparent that topics are introduced at various levels of content delivery, similar to what Thompson has found. At the global level, a major topic is introduced to explicitly inform students the content of the day, and at levels underneath the global, a sub-or minor topic is introduced to indicate a shift in discourse or topic.

In introducing major topics, lecturers make known to the students the content to be delivered and thus the introduction is most likely to concentrate at the beginning of a lecture. Nonetheless, as lectures are essentially one long discourse (Adel, 2010), which stretches from day one of the lecture to the last day of lecture (in Malaysian universities, a stretch of 15 weeks), topics to be covered within a lecture may not be single. Hence, within that same lecture, there could be more than one occurrence of topic introduction and the occurrences may take place far apart as illustrated in (01) and (02) below.

(01) okay okay today we discuss on the aggregate $<0: 2: 41>$ [Lecture_3]

(02) we proceed to the next lecture of the water and the admixture $<01: 01: 37>$ [Lecture_3]

In the two occurrences of major topic introduction in Lecture_3 above, it is clear that the first introduction of the first major topic of the lecture on Aggregate was done at the second minute, while the second introduction on Water and Admixture happened about an hour later. The introduction of the second topic, though taking place long after the lecture started indicated to the students that the lecture had another new major topic during the same lecture.

In the introduction of major topic, it is also found that lecturers specified the exact contents to be covered (03) and/or the resource in which the content covered can be located (04).

(03) so today we continue with another work example which is example nine also a welded connection with a bracket with a bracket connected to the column phase using ahh eight M M size of fillet welding [Lecture_5]

(04) I think we better start continue with our our ahh chapter two [Lecture_2]

Meanwhile, in the introduction of sub topics, it was found that there was a strong pattern that showed lecturers signalled the shift in topics by using micromarkers such as now, alright and so. The examples are shown below:

(05) now we go to the properties of aggregate [Lecture_3]

(06) alright now let us look at examples how to apply this equation in three D [Lecture_2]

(07) okay now let us take a look at the equation [Lecture_4] 
There is also a tendency for lecturers to link the new sub-topic to the previous one to signal the continuity of contents:

(08) so the new one is admixture what is admixture [Lecture_3]

\section{b. Limiting Topics}

Within the discourse function of managing topics, lecturers also stated the topics that were not really relevant at the time of speaking, underlining the fact that there is a hierarchy of importance of lecture contents. The fact that lecturers highlight that some contents should not be a concern - at least during the lecture - suggests that there is a control prescribed by the lecturers on how students should treat the contents of lectures. There are various reasons for lecturers to omit certain topics, for instance because the content was not included in the syllabus:

(09) it's not in in in your syllabus okay it's not in your syllabus so for your syllabus you have to concentrate more on braced frame for simple construction not not semi-continuous or continuous construction only for simple construction okay [Lecture_2]

Lecturers also set a limit to the topic to be covered in lectures because they wanted the students to work on their own. In the sample extracts below it is obvious that lecturers passed the responsibility to learn to the students, thus the justification for restricting the topic in lectures:

(10) I'm not going to go into very detail but you can get whatever the you know the work example given in the book [Lecture_2]

(11) so we are not going to do every of this example in the class we just concentrate on a few right the rest you can go back and try for yourself okay [Lecture_1]

In other instances, lecturers clearly omitted certain parts of the topic simply due to the complexity of the topic, and perhaps also the insignificance of topic at the time of the lecture. An example is as below:

(12) I'm not going to go into very detail because it's quite tedious [Lecture_2]

\section{c. Concluding Topics}

Similar to topic introduction, concluding or closing topics is also synonym with lectures, and is regularly employed by lecturers. Cheng (2012) argues that closings may assist students in information recall, and the generic features of lecture closings include conclusion of lecture contents and summary of key points. Just like the introductions, concluding a topic may also take place when a lecturer 
closes the discussion section on a particular (sub) topic, and thus concluding a topic may not necessarily happen only at the very end of the lecture. As Young (1994) has shown, lectures are a discourse with "many beginnings, many middles and many ends" (p.165).

Close examination of the transcripts revealed that concluding or closing of topics takes the forms of both summarizing and making conclusions as highlighted by Cheng (2012) and occurs more than once and at various parts of the lecture session, just as Young (1994) claimed. In addition, summarizing has been found to be more frequently employed than closure or conclusion and that there is an apparent pattern when lecturers gave a closure or summarized main points. First, as the name suggests, when a lecturer summarized the contents, he or she summed up the key points explained earlier in a condensed manner, yet showed attempts to ensure students have an accurate comprehension of the contents. Samples are shown below:

(13) okay we got two sets of formula so the formula actually is very much depends on the value of A effective whether is greater than zero point seven $D$ or less than zero point seven D [Lecture_2]

(14) so from the aggregate we can divide it into three specific gravity or weight yah or weight is either light weight normal and heavy heavy weight yah so these are three type you can divide the aggregate into three types [Lecture_3]

In contrast, when making a closure, the lecturers did not do any reiteration of contents, but instead gave indication that they wanted to stop talking about the contents as illustrated in (15) and (16) and that a new topic would be delivered (17).

(15) so we have seen how to apply this equations to solve the problem of the equilibrium in three dimension the equilibrium of the particle [Lecture_1]

(16) so this is how we design the size of the welding[Lecture_5]

(17) so that's water the second one is the admixture [Lecture_3]

Thus, it is apparent that closure or conclusion was repeatedly done to end a discussion of a topic at a global level, while summarizing at lower levels.

\section{Managing Phoric}

As illustrated in Table 2 above, reminding was most frequently employed by Malaysian lecturers in guiding their students in following the lectures, followed by reviews and previews and a small number of overviews. The following sub-sections present in detail the discourse functions of managing phoric as employed by the lecturers. 


\section{a. Review and Reminder}

Textual act of reviewing and reminding are common in spoken texts to facilitate access to contents mentioned previously in the discourse (Aguilar, 2008), highlighting the saliency of the previous content in relation to the current ongoing content to help facilitate listeners' interpretation and comprehension of the content. As mentioned previously, in this investigation, review and reminder are treated separately because both appear to carry distinctive characters, in terms of distribution, amount of contents included in the unit, and co-text that co-occur with either. From the analysis it is apparent that reminders are more frequently used than reviews by the Malaysian lecturers. The analysis also reveals that the occurrences of reminders are spread throughout the lectures while reviews have a tendency for a heavier concentration at the beginning of the lecture. In other words, even though both reviews and reminders point backwards in the discourse to something that has been presented before, reviews often occur at the beginning of the lesson to link the current and the previous lesson (s) as in (18) or when a subsequent new topic is introduced within the same lecture as in (19).

(18) before that I would like to give you some revision on the work example yesterday which is welded connection [Lecture_5]

(19) so if you remember that the concrete consist of the water- the cement as the main ingredient is cement okay and then cement without water is nothing yah it will not glue the aggregate [Lecture_3]

Reminders, on the other hand, are undertaken when the lecturers wish to simply "activate the audience's encyclopaedic memory and scheme" (Aguilar, 2008:230) so that students could have access to better interpretation of the current content. As such, reminders which occurred mostly during explanation of contents did not contain lengthy elaboration, but merely a brief recall that a particular content should not be treated as totally new. In some reminders, the lecturers highlighted differences between current and previous contents as in (20) or their similarities as in (21), which may help to strengthen students' understanding of both the content being presented and the overall contents of the whole lecture with the repeated mention of connections between different parts of lecture contents.

(20) if this is not a three dimensional truss if you want to analyze a- a plane truss like we did last week you should start at joint which have how many members [Lecture_4]

(21) as we did before by using the equation summation of $\mathrm{F} X$ zero summation of $\mathrm{F} Y$ zero and summation of $\mathrm{F} \mathrm{Z}$ zero no problem it will just make your work less that's all the answer will be right and i will accept that [Lecture_4] 
The verbs incorporated in the construction of reviews and reminders may have also revealed another point of difference between the two. Since reviews were more commonly used to refer to previous contents at the global or macro level, the construction seems much more elaborate as in (18) and (19) than the simplistic like we did or as we did in reminders - (20) and (21). This difference demonstrated the variation in the lecturers' linguistic behaviors in employing reviews and reminders; hence, if reviews and reminders were grouped in one category, the variations would have gone unnoticed.

There are, however, features that seem universal when lecturers look backwards to contents already covered - either by a review or a reminder. One is the inclusion of specific time adverbials, such as yesterday (22), in the first lecture (23), earlier (24) or previous example (25) which provide explicit indicative of references made:

(22) before that I would like to give you some revision on the work example yesterday which is ahh welded connection [Lecture_5]

(23) modulus of elasticity is something that we have discussed before in the first lecture also we discussed on the graph remember the stress straight graph [Lecture_3]

(24) the one that is category as heavyweight as I discussed earlier [Lecture_3]

(25) which is given in a formula as I show in the previous example F V R D [Lecture_5]

The time adverbials used highlighted the close connection between the current ongoing content and the previous (yesterday's or first lecture's) lecture contents, signifying the characteristic of the overall lecture contents which fell under one overarching topic area, regardless the stretch of time within which all lectures take place. In other words, reviews and reminders to previous contents immediate or not - are inevitable, particularly when the objective of presenting the information is didactic. In making the reference discursively explicit to students, lectures therefore employed proper time adverbial clues.

\section{a. Preview}

Another phoric marker that has been commonly examined along with reviews and reminders is preview. Similar to the use of reviews and reminders, the use of previews suggests that the lecturers are clear about the ongoing discourse structure and the constituents part of the discourse that they will present (see Burneikaite, 2008) and therefore put efforts to explicitly display the structure to mitigate the audience's load of processing the "densely related network of information delivered at relatively high speed" (Thompson, 1994: 180). Preview announces upcoming materials (Crismore, Markkanen, \& Steffensen, 1993) so that the audience could anticipate what they will encounter a while later (Hyland, 2005). In lecture discourse, upcoming contents that should be anticipated may involve a content that would be presented within the ongoing lecture itself, or at future lecture sessions which may be distantly time apart as academic lectures are one long 'text' taking place over a stretch of time (Adel, 2010). 
In these lectures, the use of previews was found to be very minimal i.e. about 2.7 occurrences in 10,000 words. Though small in number, the analysis of the linguistic behaviours surrounding previews may serve as guide for students to comprehend lectures.

As with reviews, the use of time adverbials is a common feature in the construction of previews, clearly as a means to specifically facilitate students' expectation of when the content would come. Looking at the time adverbials incorporated in previews, later (on) seems to be quite commonly used in telling when the content will again be talked about:

(26) I just introduced to you the term workability so you will hear a lot of it later on [Lecture_3]

(27) I will show to you later on in the work example actually [Lecture_2]

The use of later on indicates uncertainty about the specific time the contents to be covered. This seems logical as lectures are semi-planned and time-bound speech events which disallow a definite time for the previewed content to be presented, thus the use of later on. Yet, some degree of specificity could be detected when the lecturer used a specific future content as the indicator as in (27) above.

The use of previews in lectures may facilitate students' comprehension of lectures as they are continuously made aware of the structure and organization of contents. As Aguilar (2008) has pointed out, the basic structure of an academic speech is seldom linear, and continuous cautions of what to come would offer some reduction in processing load to the students.

\section{c. Overview}

An overview is a phoric expression which makes reference to the bigger picture of the discourse (Bunton 1999) and thus demonstrates overall connectedness in text may be useful for understanding. And in lectures, an overview normally serves as a means to maintain cohesion and coherence of the lecture content particularly one of which its discussion extends for more than one lecture meeting:

(28) there are so many things that we need to discuss as far as aggregate is concerned what is aggregate what is natural aggregate what is cast aggregate what is the effect of the shape of aggregate the texture the grade etcetera so these are the things that I would like to cover this morning [Lecture_3]

(29) we will concentrate more on steel section actually we will concentrate more on determinate structure okay it's not something like concrete you know whereby everything considered as rigid but in in steel you need to classify the construction the construction is it considered as a simple construction semi continuous or continuous construction and is very much depend on the the connection [Lecture_2]

As demonstrated in Table 2 above, overview was less likely to be used among the lecturers. In fact, the analysis showed that there was no occurence of overview that provides connections of contents at 
the global level i.e. the explicit expressions of how contents are connected across several lecture sessions. All the overviews identified are at the local level as in (28) and (29) above. Looking closely at the extracts, it is clear that the construction of overviews also seems unclear. There was no use of sequencers such as first or and then - for examples - that could make the overview explicit and consequently easy to follow by the students. These overviews which were rather hazy gave a possibility that the bigger structure of content becomes unclear to the students and therefore offered little help in facilitating comprehension.

\section{Discussion}

This paper has explored metadiscourse in five undergraduate engineering lectures in the context of the Malaysian higher education with the aim to gain insights into how metadiscourse is employed in such lectures with a specific focus on discourse functions of managing topics and managing phoric. Of the two, Malaysian lecturers were found to employ more managing topic than phoric when delivering lectures. The most frequent discourse function in managing topic is introduction of topics both at major and sub levels. As for managing phoric, the act of reminding was the most employed discourse function by the Malaysian lecturers. These uses are indicative that lecturers are concerned about the coherence and interconnectedness of contents which are essential for students to follow and understand the lectures.

The patterns of metadiscourse observed in this study may be related to three influential factors. The first is lectures as a genre which is attached to didactic as the primary objective. Bjorkman (2010) claims that in a non-native academic setting where English is used as the medium of instruction, lecturers not only have to focus on content delivery but they also have to pay attention at strategizing on how to ensure students comprehend the contents delivered effectively. The demands to ensure comprehensible delivery may put a great pressure on the lecturers, particularly as they are aware that students have a varying degree of English language proficiency which have direct consequences in the ability to understand the lecture contents. Thus, marking introduction of topics and subtopics as well as reminders may be favoured as these could guide students to follow the lectures more easily.

The engineering contents may also play a role in deciding metadiscourse employed. The engineering subjects that deal with abstract and technical representation of reality require students to understand concepts, processes or phenomena that are specific. The fact that the subjects are second year subjects further amplify the requirements for solid understanding and thus calls for effective transmission of fundamental knowledge that serves as basics for the discipline (Aguilar, 2008). The subjects that are densely factual and deal with problem solving offer "non-argumentative catalogues of facts" (Olsen and Huckin, 1990, p 41) and thus lecturers were left with not many options, but to ensure students were able to follow and understand the contents.

The concentration of some features of metadiscourse used could also be related to the use of English as a medium of instruction. When English is used as the medium of instruction, there is some degree of pressure on the lecturers to be pedagogically functional and effective when delivering lectures (Bjorkman, 2010). While the lecturers were no doubt competent in transmitting lecture contents, they may have a limited linguistic repertoire to be used, and thus overusing some 
metadiscourse while ignoring others. The obvious patterns are the high frequency of introducing topics and referring backward and lack of previewing and overviewing. Needless, the limited variety of metadiscourse used does not understate the fact that lectures are didactic and are for knowledge transmission.

\section{CONCLUSION AND PEDAGOGICAL IMPLICATIONS}

The investigation has only analysed a small number of engineering lectures in the Malaysian tertiary context; yet the findings have revealed actual and naturally-occurring practices in Malaysian lectures that would be otherwise unknown. What the findings have highlighted are that Malaysian lecturers are aware of the demands of comprehending academic lectures and that the students need guidance in understanding the lectures. The discourse functions that have been found comprise those that would direct students on how to follow what is delivered. As commonly agreed, metadiscourse in spoken text is an aspect of language that speakers use to shape the discourse by organizing, describing and commenting on the discourse to guide hearers in interpreting and understanding the discourse. Based on the lectures analysed, it is clear that lecturers used language to ensure students were able to follow and process the contents delivered to them. Given its centrality, metadiscourse would offer important pedagogical implications.

This study suggests that metadiscourse should be included in young beginning lecturer training programmes. Many lecturers are not trained to deliver effective lecture (Morell, 2004), thus informed trainings derived from findings of the study and activities that draw from real experiences may stimulate self-awareness and reflection on appropriate use of metadiscourse during lecture delivery (Molino, 2018). Considering the results obtained in this study, attention could be focused, for instance, on ways in which metadiscourse is used for topic management and phoric management, complete with samples of specific linguistic features that may develop and promote strategic deployment of metadiscourse for an effective lecture delivery.

Students should also be exposed to metadiscourse that are used in lectures for more effective listening comprehension skills. Students could be made aware that there are various tasks pertinent to lecture delivery and that lecturers make use of different linguistic repertoire to achieve their objectives. Samples drawn from authentic lecture scripts could help students recognise the complexities of language of lectures and range of meanings of metadiscourse used in lectures. This paper has contributed to the knowledge on how language is employed in engineering lectures particularly in a non-native context. Though it is based on only five lectures, it has provided a breakthrough in looking at the nature of engineering lectures in Malaysia and helped highlighting that a complex and multifaceted genre as lectures need further investigations so that both lecturers and students could benefit from knowledge on a variety of lexical and grammatical resources used in lectures for better lecture delivery and lecture comprehension. 


\section{REFERENCES}

Ädel, A. 2010. 'Just to Give you Kind of a Map of Where We are Going': A Taxonomy of Metadiscourse in Spoken and Written Academic English. Nordic Journal of English Studies. 9(2): 69-97.

Aguilar Pérez, M., \& Arnó Macià, E. 2002. Metadiscourse in Lecture Comprehension: Does it Really Help Foreign Language Learners? Atlantis. 24(1): 7-21.

Aguilar, M. 2008. Metadiscourse in Academic Speech: A Relevance-Theoretic Approach. Peter Lang.

Ahmed, A., \& Masroor, F. 2018. Exploring Argumentation in Print Media: A Comparative Metadiscourse Analysis of British and Pakistani English Newspapers' Letters to the Editor. Kashmir Journal of Language Research. 21(2).

Albalat-Mascarell, A., \& Carrió-Pastor, M. L. 2019. Self-representation in Political Campaign Talk: A

Functional Metadiscourse Approach to Self-Mentions in Televised Presidential Debates. Journal of Pragmatics. 147: 86-99.

Ali, A. Q. 2016. Metadiscourse Markers in Advanced EFL Learners' Academic Writing. hawlyat al_montada. 1(28): 19-38.

Biber, D., \& Barbieri, F. 2007. Lexical Bundles in University Spoken and Written Registers. English for Specific Purposes. 26(3): 263-286.

Björkman, B. 2010. So You Think You Can ELF: English as a Lingua Franca as the Medium of Instruction. HERMES-Journal of Language and Communication in Business. (45): 77-96.

Bunton, D. 1999. The Use of Higher Level Metatext in Ph.D Theses. English for Specific Purposes. 18: S41-S56.

Burneikaitè, N. 2008. Metadiscourse in Linguistics Master's Theses in English L1 and L2. Kalbotyra. 59: 38-47.

Pastor, M. L. C. 2016. A Contrastive Study of Interactive Metadiscourse in Academic Papers Written in English and Spanish. In Corpus-based Studies on Language Verieties (pp. 89-114). Peter Lang.

Chaudron, C., \& Richards, J. C. 1986. The Effect of Discourse Markers on the Comprehension of Lectures. Applied Linguistics. 7(2): 113-127.

Cheng, S. W. 2012. "That's it for Today": Academic Lecture Closings and the Impact of Class Size. English for Specific Purposes. 31(4): 234-248.

Camiciottoli, B. C. 2007. The Language of Business Studies Lectures: A Corpus-assisted Analysis. Vol. 157. John Benjamins Publishing.

Crismore, A., \& Farnsworth, R. 1990. Metadiscourse in Popular and Professional Science Discourse. The Writing Scholar: Studies in Academic Discourse. 118-136.

Crismore, A., Markkanen, R., \& Steffensen, M. S. 1993. Metadiscourse in Persuasive Writing: A Study of Texts Written by American and Finnish University Students. Written Communication. 10(1): 39-71.

Deroey and Taverniers, 2011 Deroey, K., \& Taverniers, M. 2011. A Corpus-based Study of Lecture Functions. Moderna Spark. 105(2): 1-22. 
Deroey, K. L., \& Taverniers, M. 2012. Just Remember This: Lexicogrammatical Relevance Markers in Lectures. English for Specific Purposes. 31(4): 221-233.

Dorodkhan, S. J., \& Kiasi, G. A. 2016. Discourse Markers Instruction and Listening Comprehention Ability. Modern Journal of Language Teaching Methods. 6(4): 110.

Ebrahimi, S. J. 2018. The Role of Metadiscourse Markers in Comprehending Texts of Reading Comprehension Books Published in Iran and Oxford University Press. International Journal of Applied Linguistics and English Literature. 7(3): 90-96.

Flowerdew, J., Long, M. H., \& Richards, J. C. (Eds.). 1994. Academic Listening: Research Perspectives. Cambridge University Press.

Hu, G., \& Cao, F. 2015. Disciplinary and Paradigmatic Influences on Interactional Metadiscourse in Research Articles. English for Specific Purposes. 39: 12-25.

Hyland, K., \& Jiang, F. K. 2018. "In This Paper We Suggest": Changing Patterns of Disciplinary Metadiscourse. English for Specific Purposes. 51: 18-30.

Hyland, K. 2005. Metadiscourse: Exploring Interaction in Writing. London, UK: Continuum.

Hyland, K. 2017. Metadiscourse: What Is It and Where Is It Going? Journal of Pragmatics. 113: 1629.

Ibrahim, N. M. 2015. Forms and Communicative Intent of Metadiscourse in Malaysian and British Undergraduate Engineering Lectures (Doctoral Dissertation, Universiti Teknologi Malaysia).

Kawase, T. 2015. Metadiscourse in the Introductions of PhD Theses and Research Articles. Journal of English for Academic Purposes. 20: 114-124.

Khuwaileh, A. A. 1999. The Role of Chunks, Phrases and Body Language in Understanding CoOrdinated Academic Lectures. System. 27(2): 249-260.

Kim, I. H. 2017. Metadiscourse in Persuasive Essays by Elementary Students in South Korea and the US. Journal of Language and Cultural Education. 5(2): 80-102. MacDonald, M., Badger, R., \& White, G. 2000. The Real Thing? Authenticity and Academic Listening. English for Specific Purposes. 19(3): 253-267.

Liu, C. Y., \& Chen, H. J. H. 2020. Analyzing the Functions of Lexical Bundles in Undergraduate Academic Lectures for Pedagogical Use. English for Specific Purposes. 58: 122-137.

Mauranen, A. 1993. Contrastive ESP Rhetoric: Metatext in Finnish-English Economics Texts. English for specific Purposes. 12(1): 3-22.

Mauranen, A., Hynninen, N., \& Ranta, E. 2010. English as an Academic Lingua Franca: The ELFA Project. English for Specific Purposes. 29(3): 183-190.

Mohamed, M. 2008. Globalization and Its Impact on the Medium of Instruction in Higher Education in Malaysia. International Education Studies. 1(1): 89-94.

Molino, A. 2018. What I'm Speaking Is Almost English...': A Corpus-Based Study of Metadiscourse in English-Medium Lectures at an Italian University. Educational Sciences: Theory and Practice. 18(4): 935-956.

Morell, T. 2004. Interactive Lecture Discourse for University EFL Students. English for Specific Purposes. 23(3): 325-338.

Nesi, H. 2012. Laughter in University Lectures.Journal of English for Academic Purposes. 11(2): 79-89. 
Olsen, L. A., \& Huckin, T. H. 1990. Point-driven Understanding in Engineering Lecture Comprehension. English for Specific Purposes. 9(1): 33-47.

Robinson, S. L., Sterling, H. E., Skinner, C. H., \& Robinson, D. H. 1997. Effects of Lecture Rate on Students' Comprehension and Ratings of Topic Importance. Contemporary Educational Psychology. 22(2): 260-267.

Salas, M. D. 2015. Reflexive Metadiscourse in Research Articles in Spanish: Variation across Three Disciplines (Linguistics, Economics and Medicine). Journal of Pragmatics. 77: 20-40.

Scott, M. 2008. Developing Wordsmith. International Journal of English Studies. 8(1): 95-106.

Simpson, R. C., \& Swales, J. M. (Eds.). 2001. Corpus Linguistics in North America: Selections from the 1999 symposium. University of Michigan Press.

Thompson, S. E. 2003. Text-structuring Metadiscourse, Intonation and the Signaling of Organization in Academic Lectures. Journal of English for Academic Purposes. 2(1): 5-20.

Tauroza, S., \& Allison, D. 1990. Speech Rates in British English. Applied Linguistics. 11(1): 90-105.

Vande Kopple, W. J. 1985. Some Exploratory Discourse on Metadiscourse. College Composition and Communication. 82-93.

Vásquez, C. 2015. “Don’t Even Get Me Started...”: Interactive Metadiscourse in Online Consumer Reviews. In Digital business discourse (pp. 19-39). Palgrave Macmillan, London.

Young, L. 1994. University lectures: Macro-structure and Micro-features. In J. Flowerdew (Ed.). Academic Listening: Research Perspectives (pp. 159-176). Cambridge, UK: Cambridge University Press.Thompson. 1994: 180 